\title{
MORPHO-PHYSIOLOGICAL AND ANATOMICAL ASSESSMENT OF DIFFERENT RICE VARIETIES SUBJECTED TO DROUGHT STRESS AT EARLY VEGETATIVE STAGE
}

\author{
MOHD FAUZIHAN KARIM*, NUR FARAH SUHADA MOHD ROSELY, NUR AINI MOHD KAMIL \\ and CHE NURUL AINI CHE AMRI \\ Department of Plant Science, Kulliyyah of Science, \\ International Islamic University Malaysia, \\ 25200 Kuantan, Pahang, Malaysia \\ *E-mail: mfauzihan@iium.edu.my
}

Accepted 6 February 2021, Published online 30 March 2021

\begin{abstract}
Drought is a climate problem which has become a major constraint on crop production and causing social and economic devastation to local farmers worldwide. This climate issue has been the most destructive factors for rice cultivation and therefore requires scientist to be more responsive to this problem. In this study, we investigated the effect of drought stress at an early vegetative stage on plant growth, physiology and root anatomy of a few selected known tolerance rice varieties. Rice seeds were first germinated on moisturized filter papers before transplanted into polybags filled with topsoils. Drought treatment was imposed 4 weeks after transplanting until the first sign of rolled leaves were seen. In this study, drought had no major impact on plant height but reduced dry matter accumulation was seen in all varieties. Drought exposure had also triggered changes in the overall content of chlorophyll but not in the composition of chlorophyll $a$ and $b$. Meanwhile, plants subject to drought in some parameters had better root morphology and structure compared to normal irrigation, especially in Kuku Belang, Apami and Huma Wangi Lenggong. However, depending on the variety, the responses varied in different order of magnitude.
\end{abstract}

Key words: Acclimation, anatomy, drought stress, growth, rice

\section{INTRODUCTION}

Rice or Oryza sativa L. is one of the best sources of carbohydrates and energy for humans. Rice intake accounts for approximately $60 \%$ of total diets in the population of Southeast Asia, and 35\% in East and South Asia. The ASEAN (Association of Southeast Asian Nations) countries like Cambodia, Indonesia, Laos, Myanmar, Thailand, and Vietnam are among the peoples' largest per capita rice consumers during the year (Dunna \& Roy, 2013). In many countries, the importance of rice has always been tied to food security, and ongoing efforts have been made to keep pace with people's increasing demands. Nevertheless, efforts are also interrupted by rapid urbanization and industrialization where the freshwater crisis in many parts of the world is becoming a serious issue (Weller et al., 2016).

* To whom correspondence should be addressed.
Meanwhile, rice production in Malaysia was approximately $2.8(0.4 \%)$ million tons out of the total Asian production of 656.4 million tons. The country generates $70 \%$ of its self-sufficiency rates compared to its domestic demand, while the remaining 30\% have been mainly imported from Thailand, Vietnam, and Pakistan. The import of rice in 2015 was calculated to be around 960000 tonnes and the numbers are expected to rise around 1.347 billion tonnes in 2020 due to population increase (FAO, 2018). It is a cause for concern since the inability to increase production capacity could lead to a food crisis in the country, especially in the emergency or pandemic situation. The effort to introduce new paddy fields in the country seemed to be an alternative way to increase rice production. However, despite the hard efforts of farmers, climate uncertainty has become the biggest challenge to plant productivity, as has been the case in many other new paddy fields. 
Low rice production is believed to have been affected by several external factors, including a lack of technology and global climate change. Increased environmental stress, including high temperatures, precipitation shortfalls, and overflow, all of which have been partly driven by climate change (Arnell et al., 2019). Droughts have, among other things, been persistently threatening and have caused more crop yield damage and probably more losses than any other environmental stress, with disastrous consequences for the economy, society, and the environment (Farooq et al., 2009; Naumann et al., 2018). Drought can be referred to as prolonged periods of an abnormal rainfall deficit resulting in water shortage, crop damage, degradation of streamflow and groundwater or reduction of soil moisture, a disruptive natural disaster that may cause a decreasing number of sectors (Fadhilah et al., 2012). As a high water-consuming crop, around $76 \%$ of the global rice cultivations are irrigated paddy fields. Thus, rice production relies heavily on the availability of freshwater, rendering it vulnerable to drought stress in the region where water is often scarce (Fageria, 2007; Pandey et al., 2007).

One of the strategies for enhancing crop production in drought-prone areas is to look at the root phenotype of drought tolerance. Root features have been said as being important and crucial to increasing drought tolerance in plants (Pandey \& Shukla, 2015; Messina et al., 2015). The development of root anatomy and structure will largely determine crop function under drought especially in rice (Mostajeran \& Rahimi, 2008; Singh et al., 2013; Ouyang et al., 2020). To obtain new crops that are tolerant to climate change, having different root characteristics might be required compared to the sensitive domestic trait. This research has therefore been conducted to study the performance of rice growth through morpho-physiological and anatomical approaches among the few selected rice varieties since the study on the response of rice to drought stress is still inadequate, especially about root behaviour.

\section{MATERIALS AND METHODS}

The experiment was conducted at the Glasshouse and Nursery Complex (GNC), International Islamic University Malaysia, Kuantan, Pahang. In this experiment, six varieties were tested; Kuku Belang, Apami, Pulut Malaysia 1, Merah Wangi, Huma Wangi Lenggong, and MR297 that were obtained from the Rice Gene Bank, MARDI Seberang Perai, Pulau Pinang, Malaysia. These varieties were selected because they suggested high resilience against drought condition except for MR297 (Salleh, 2020). The seeds were first germinated on moisturized filter papers before transplanted into polybags filled with $100 \%$ topsoils from Kuantan series. After 28 days of transplanting, drought was imposed by stopping the watering until the first sign of rolled leaves were seen on any plant $(-45 \mathrm{kPa})$. In this research, it was not re-watered for all types when subjected to drought to detect how resilient it would be and for imitating the actual non-rainfall in a field where the situation without water would usually exceed 7 days. Meanwhile, for normal watering, the water level was maintained at $3-5 \mathrm{~cm}$ above the plant's basal point (Salleh et al., 2018). The domestic widely grown MR219 variety was used as a positive control in this study.

\section{Plant height}

The data for plant height were obtained by measuring the plant from the basal to the youngest tip of the leaf shoot. The measuring was done shortly before harvesting the plant to reflect the final achievement of height affected by the treatments.

\section{Total biomass}

For total plant biomass, the entire plant components including leaves, culms, and roots were harvested and washed off from any loose soil. The specimens were then air-dried in a ventilated oven at $68^{\circ} \mathrm{C}$ until the constant weight was achieved.

\section{Total content and composition of chlorophylls}

Total chlorophyll content was measured according to Porra et al. (1989) with minor modification. Fresh weight of leaves was homogenized using a pestle and a mortar in $10 \mathrm{~mL}$ of $80 \%$ acetone. The extracts were centrifuged for $10 \mathrm{~min}$ at $9000 \mathrm{rpm}$ and the supernatant was collected, the chlorophyll content was measured using a spectrometer and calculated as below:

$$
\begin{gathered}
\text { Chl } a=13.71 . \mathrm{A}_{(663.6-750)}-2.85 . \mathrm{A}_{(646.6-750)} \\
\text { Chl } b=22.39 . \mathrm{A}_{(663.6-750)}-5.42 . \mathrm{A}_{(646.6-750)} \\
\text { Chl } a+b=19.54 . \mathrm{A}_{(663.6-750)}+8.29 . \mathrm{A}_{(646.6-750)}
\end{gathered}
$$

Where $\mathrm{A}_{(\mathrm{X}-750)}$ is the difference in absorbance between $\mathrm{X} \mathrm{nm}$ and $750 \mathrm{~nm}$.

\section{Root anatomy}

Root samples were cut at $5 \mathrm{~cm}$ from the root tips and cut in a thickness range $(50-100 \mu \mathrm{m})$ using a sliding microtome and stained in Safranin and Alcial blue for approximately 15 minutes. The sectioned roots were then placed on a slide with a few drops of distilled water before covering it with a cover slide (Metcalfe \& Chalk, 1979; Noraini, 2006). Images of root anatomy were observed under a compound microscope at $4 \mathrm{x}$ magnification (scale bar at $0.2 \mu \mathrm{m}$ ) using Leica LAS EZ software. 


\section{Statistical analysis}

The statistical test was performed using SigmaPlot analysis software. The data were analyzed by using the Analysis of Variance (Two-way ANOVA) at 5\% level to determine the significant difference among treatments. The level of significance was accepted at $p \leq 0.05$ (Tukey test).

\section{RESULTS AND DISCUSSION}

This experiment was done to evaluate the potential resilience of few selected Oryza sativa L. varieties when subjected to drought treatments at the seedling stage including MR297, Kuku Belang, Apami, Huma Wangi Lenggong, Pulut Malaysia 1 and Merah Wangi. Previous research showed that proper irrigation during the vegetative stage could be the most crucial, as it could decide the later stage of rice production (Fukai et al., 1999; Inthavong et al., 2011; Ji et al., 2012; Trijatmiko et al., 2014). It was previously reported that drought occurring during the vegetative stage consequence in $21 \%-50.6 \%$ rice yield reduction (Guan et al., 2010; Sarvestani et al., 2008). During this level, in particular water and temperature stress, the plant is in the process of active growth but too fragile to any external environmental influence.

For this research, there was no re-watering done to see how robust it would be for every variety when it was subjected to drought. After the last watering, all plants were introduced with continuous drought stress and stopped when the first sign of rolling leaves was seen in any of the plants. Based on our findings, drought had no effect on plant height at the seedling stage (Figure 1). However, it was found to be significant amongst varieties in both drought stress and normal condition. Kuku Belang reported the highest plant height in drought stress while Huma Wangi Lenggong was the lowest. Nevertheless, data on plant height was not correlated with a total accumulation of dry weight. As illustrated in Figure 2, the dry matter was substantially affected by drought in all varieties with a reduction from $19 \%$ to $44 \%$ relative to their normal state. The durability towards drought in each variety was also different with Pulut Malaysia 1 recorded the highest whilst Merah Wangi was the most affected.

In multiple plant development, morphophysiological parameters including plant height and accumulation of dry matter may be a simple but important indicator for survival rate and growth analysis. During drought, stomata were reported to close to avoid continuous water loss on the path of transpiration (Pirasteh-Anosheh et al., 2016). This has a trading effect, however, in which carbon assimilation for photosynthesis is decreased and thus dry matter accumulation is reduced. Drought during the vegetative process limits the growth of the root system, which in turn decreases the area of the leaves, the number of leaves per plant, the size and the longevity (Boonjung \& Fukai, 1996). However, the resilience characteristic of rice towards drought is variety and genotype dependent (Serraj et al., 2011). Due to their native localization, different responses among varieties were expected in this

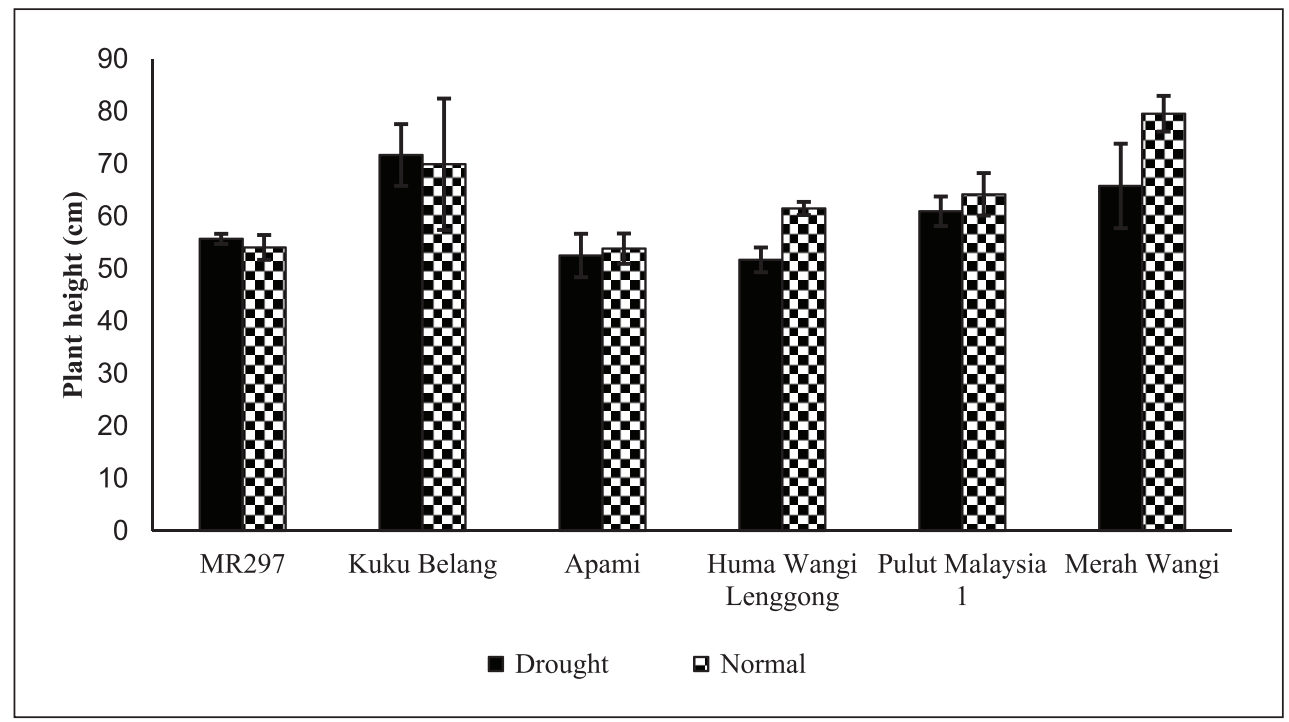

Fig. 1. Effect of drought stress on plant height of few selected Oryza sativa L. varieties at early vegetative stage. Each bar represents the mean and standard error from three biological replicates (Tukey, $n=3$ ). The drought did not affect plant height at the seedling stage. However, it was found to be significant amongst varieties in both drought stress and normal condition (Two-way ANOVA at $p \leq 0.05$ ). 


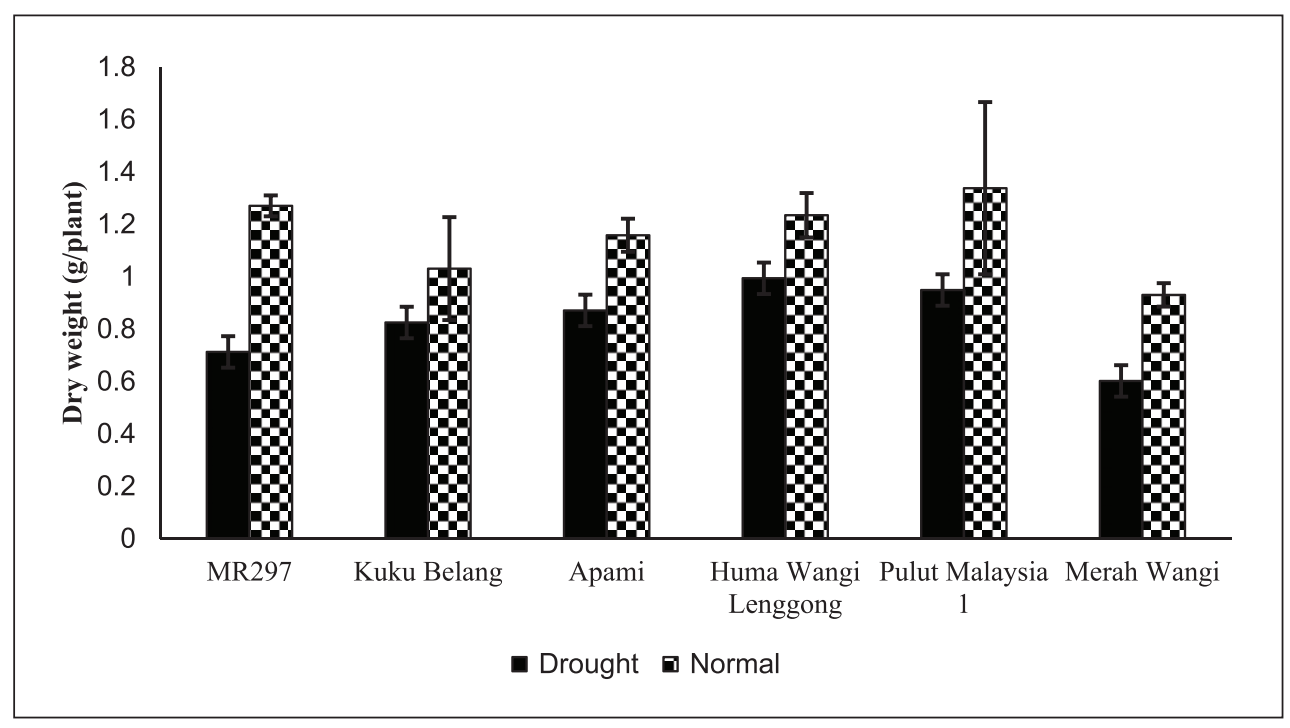

Fig. 2. The effect of drought stress on dry weight accumulation of few Oryza sativa L. varieties at early vegetative stage. Each bar represents the mean and standard error from three biological replicates (Tukey, $n=3$ ). In this experiment, drought and varieties had significantly affected the accumulation of total dry weight (Two-way ANOVA at $p \leq 0.05$ )

study. Kuku Belang and Huma Wangi Lenggong are both from rain-fed upland varieties whilst Apami, Merah Wangi, and MR297 are all lowland types. Therefore, we propose that the lower decrease observed in Kuku Belang and Huma Padi Lenggong $(19 \%$ \& $20 \%$, respectively) is due to their morphological and genetic variances in upland drought stress. The high tolerance characteristic of upland rice germplasm has been used to improve drought tolerance through hybridization with highyielding characteristics of lowland cultivars ( $\mathrm{Gu}$ et al., 2012).

The examination of leaf sensitivity to drought stress was proceeded by calculating the total content of chlorophyll from growing plant's fully formed leaf. Chlorophylls are responsive green pigments incorporated in chloroplast into the thylakoid membrane, and prolonged drought is known to weaken the structure and contribute to photosynthesis cycle dysfunction. The concentration of chlorophyll content was recognized as a source of measurement index, which was considered to be a non stomatal limiting factor in the state of drought stress (Khayatnezhad \& Gholamin, 2012). It was also suggested as a reliable parameter in screening germplasm for drought tolerance (Li et al., 2006). Based on the finding, drought had significantly reduced the total chlorophyll content in leave samples especially in MR297, Apami, and Merah Wangi compared to their respective normal watering (41\%, 38\% and $47 \%$, respectively) (Figure 3). However, both Apami and MR297 were still higher in chlorophyll than few other varieties, including Merah Wangi and Pulut Malaysia 1. The Kuku Belang meanwhile registered the highest total chlorophyll followed by Apami and Huma Wangi Lenggong. According to Rahbarian et al. (2011), the content of photosynthetic pigment including chlorophyll $a / b$ was reduced under water stress. Reductions in chlorophyll content have been reported to slow down the activity of photosynthesis (Mafakheri et al., 2010). This may be the point of reference for lower dry matter decreases in Kuku Belang, Apami, and Huma Wangi Lenggong (Figure 2).

While total chlorophyll is an indicator of a healthy plant, the Chlorophyll $a: b$ provides the information of the composition between Chl $a$ in the Photosystem II (PSII) reaction centers and the $\mathrm{Chl} b$ that is only found in the light-harvesting complex (LHC). In the case of drought, the reduction of Chl $b$ was higher than that of $\mathrm{Chl} a$, thus increasing the ratio for Chl a (Jaleel et al., 2009; Jain et al., 2010). The ratio Chl $a: b$ is, therefore, a sensitive indicator of changes in the relative composition of the lightharvesting systems within a leaf. Based on Figure 4, the numbers of Chlorophyll- $a$ in the reaction centers were balanced with the number of antenna presence in the thylakoid membrane. It can therefore be seen that, in this analysis, drought results in altered total content but not the chlorophyll composition.

The investigation of root traits in this study also explored the potential of high tolerance characteristics in all varieties tested for drought stress. Despite several studies examining different aspects of growth and development of paddy under drought stress, there is often a lack of a direct link to the functionality of root development for tolerance. It leads to less access to learning more about what is happening in this essential organ 


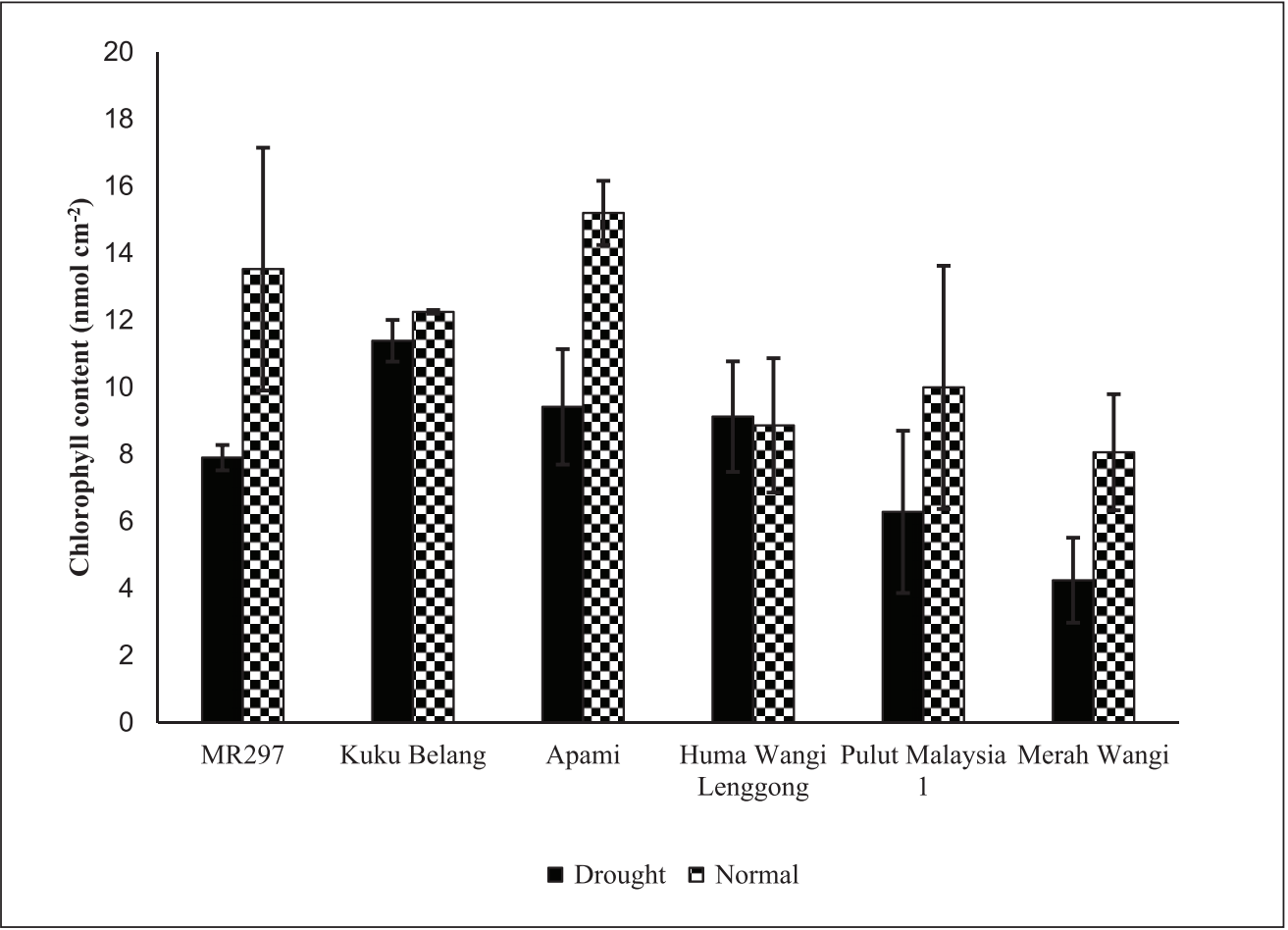

Fig. 3. The effect of drought stress on chlorophyll content of Oryza sativa L. varieties at early vegetative stage. Each bar represents the mean and standard error from three biological replicates (Tukey, $n=3$ ). In this experiment, drought and varieties had significantly affected the formation of chlorophylls in leaves (Two-way ANOVA at $p \leq 0.05$ ).

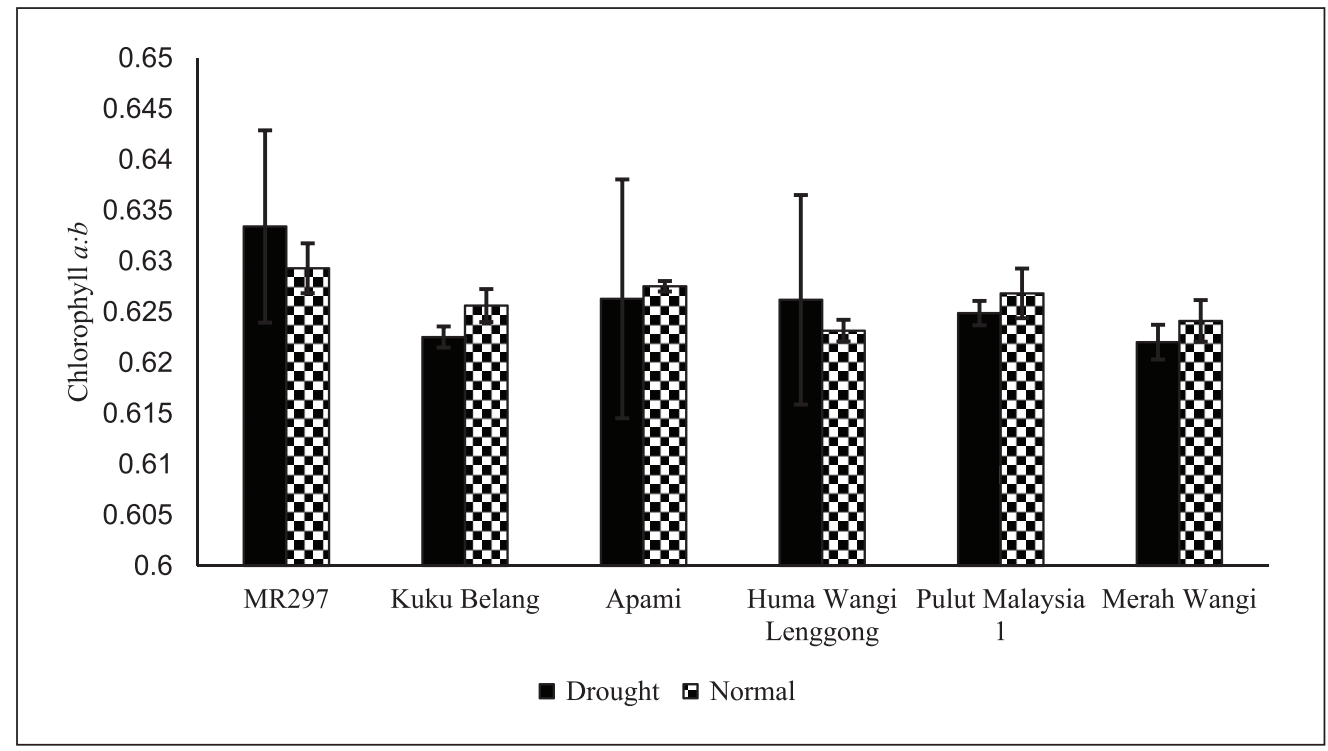

Fig. 4. The effect of drought stress on chlorophyll composition of Oryza sativa L. varieties at early vegetative stage. Each bar represents the mean and standard error from three biological replicates (Tukey, $n=3)$. The drought had a significant effect on the chlorophyll composition in leaves at the seedling stage. However, it was found that there was no significant amongst varieties (Two-way ANOVA at

during a drought in rice. This research focused on the differentially modified root structure of these selected varieties of rice affected by drought stress. The images of root tissue were captured using the same bar scale $(0.2 \mu \mathrm{m})$ of which all images of the crossed section could be observed clearly. According to Figure 5, although a sign of shrinkage has been seen in all drought-induced root samples, was nonetheless showed larger in diameter $(11 \%$, $56.3 \%, 57.6 \%, 34.1 \%, 17.6 \%$ in MR297, Kuku Belang, 


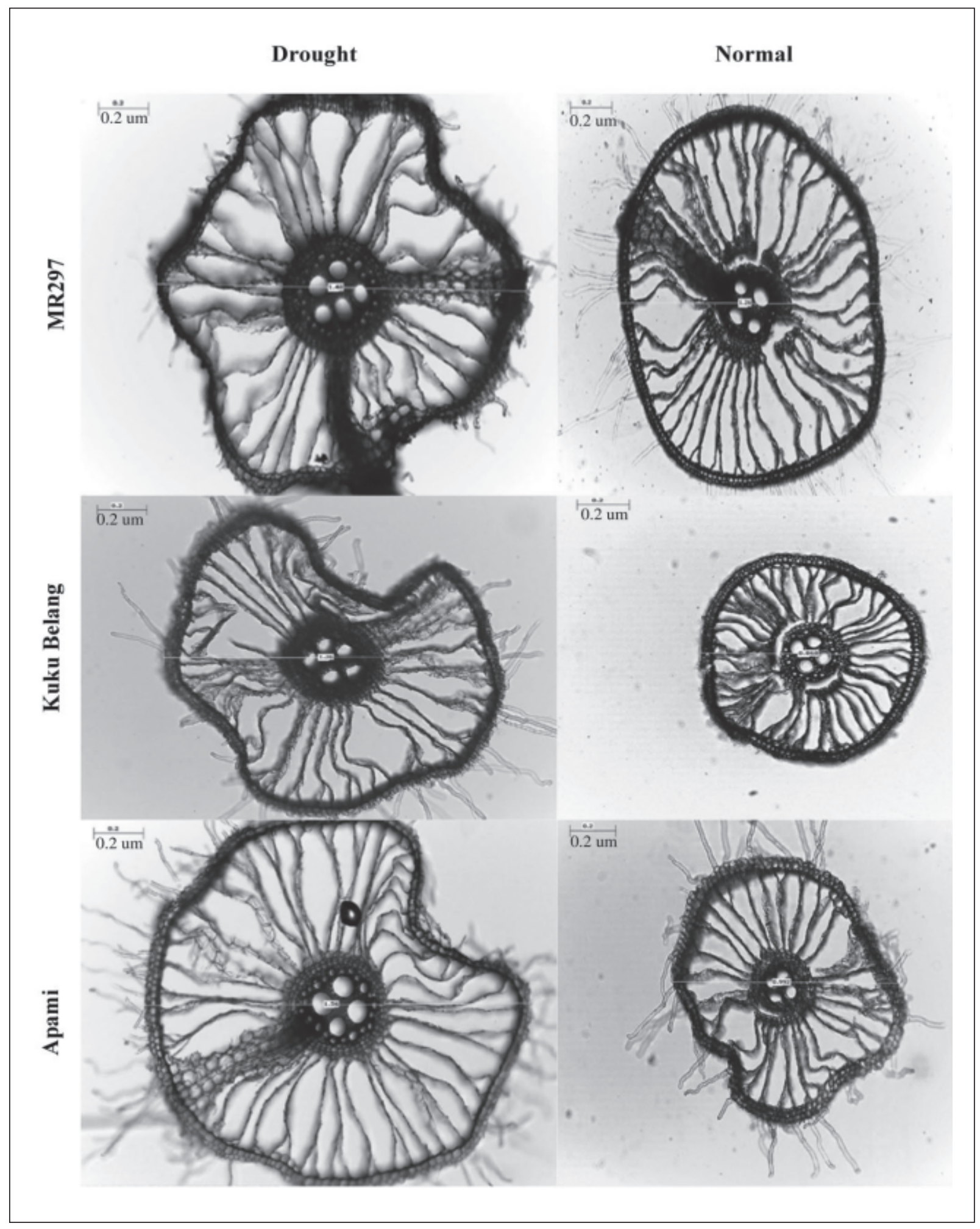




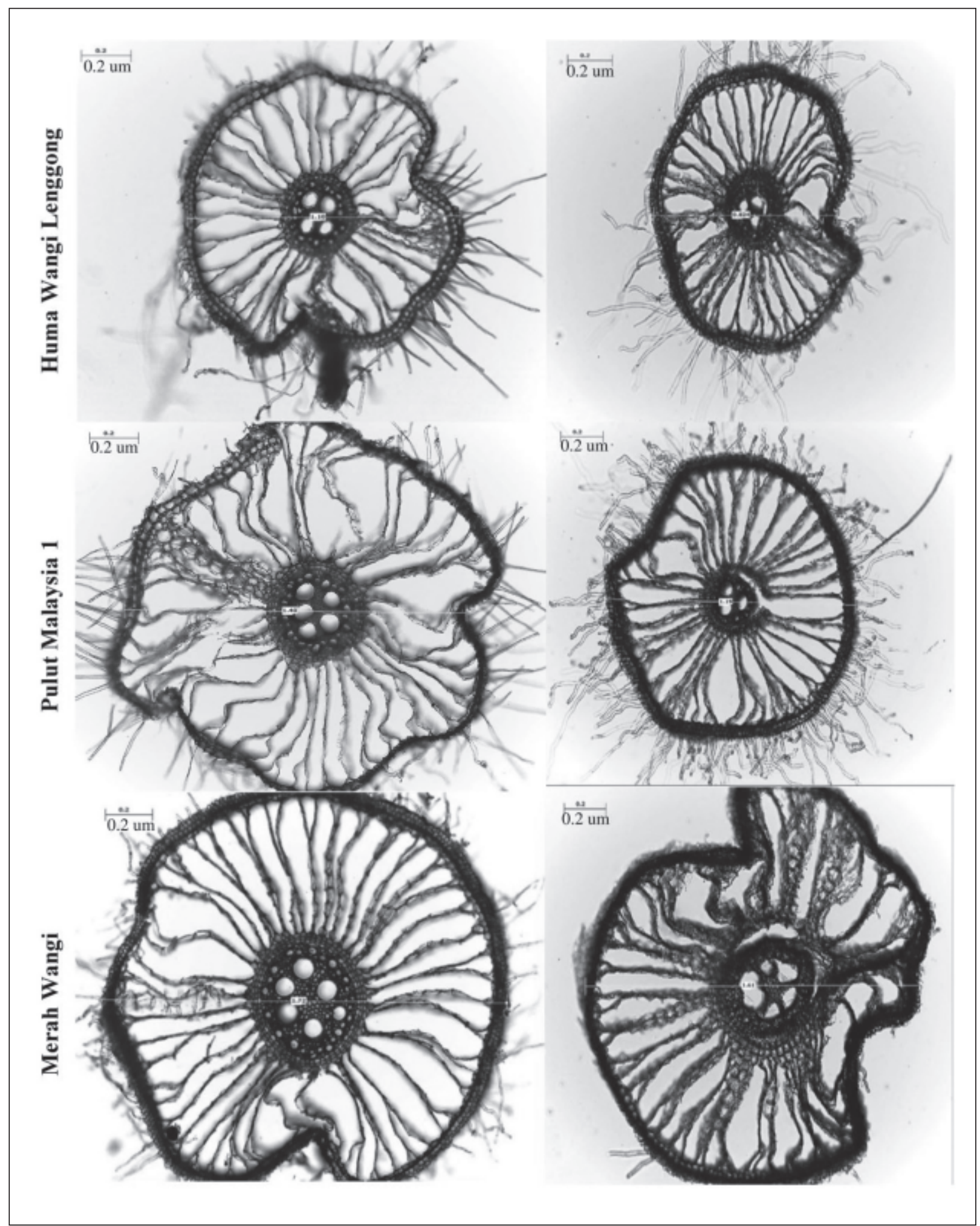

Fig. 5. The effect of drought stress on root anatomy of Oryza sativa L. varieties at early vegetative stage. Images of root anatomy were observed under a compound microscope at $4 \mathrm{x}$ magnification (scale bar at $0.2 \mu \mathrm{m}$ ) using Leica LAS EZ software. 
Apami, Huma Wangi Lenggong and Pulut Malaysia 1 , respectively) compared to that of their respective normal condition with exception to Merah Wangi $(-6.4 \%)$. Also, the number and type of metaxylem in drought stress plants were better than control except in Merah Wangi. Metaxylem is likely to be associated with maintaining conductivity and presumably as an advantage in increasing the extraction of water from deeper soil layers (Singh et al., 2013). Meanwhile, the diameter of the xylem was also stated to be proportional to the root diameter, maximizing water access and productivity under water shortages (Wang et al., 2018).

In this analysis, larger aerenchyma tissues were found in Kuku Belang, Apami, Huma Wangi Lenggong, and Pulut Malaysia 1 seedlings grown during the drought as against their normal water status. Rice is a semi-aquatic cereal that is usually grown under flooded conditions and thus aerenchyma tissue has been recognized as an anatomical adaptive feature essential for survival under flooded conditions that provides a lowresistance diffusion route for oxygen transport (Kawai et al., 1998; Pradhan et al., 2016). In the sense of drought stress, however, the production of greater root aerenchyma was suggested as an acclimation strategy for increasing the tolerance of droughts in plants as portrayed in this study. Root aerenchyma was reported to reduce root respiration in the plant by converting living cortical tissue to air volume (Zhu et al., 2010). The increase of aerenchyma tissue under drought also helped to reduce the root metabolic costs, enabling better root growth and better water extraction from drying soil (Zhu et al., 2010).

Furthermore, the production of root hair in plants was a sign of response to a reduction in soil moisture and could compensate for a reduction in root elongation by increasing the surface area in dry soil (Mackay \& Barber, 1985: Bates \& Lynch, 2001; Wasson et al., 2012). In the present study, all plants have had varying responses in the formation of root hairs under drought. Both Kuku Belang and Apami showed more proliferation of root hair compared to their control, while Huma Wangi Lenggong was visibly almost the same as normal watering. However, drought stress was found to seriously affect the growth of the root hair in both MR297 and Merah Wangi. Extreme water stress has been reported to increase soil resistance and thus inhibit root growth and development to deepen water exploration in the soil (Comas et al., 2005). Nevertheless, reduced growth of the main roots will be offset by the development of more root hairs (Vandeleur et al., 2009; Laur \& Hacke, 2013). Therefore, we propose that Kuku Belang and Apami have a stronger root acclimatization cycle to withstand a deficit of water at an early vegetative stage. Nevertheless, to understand more on the details that contribute to the competency of these varieties, we do suggest a cytogenetic approach be included in future research to look into the cell cycle and division.

\section{CONCLUSION}

In this study, we conclude that few tested varieties were seen as having the capacity to withstand drought stress at an early vegetative stage. This includes two upland varieties (Kuku Belang and Huma Wang Lenggong) as well as one rainfed lowland variety (Apami) based on the data in all parameters assessed. Meanwhile, in terms of morphophysiology, MR297, the commonly grown low soil type, was moderately affected. Additionally, the data also showed poor root acclimatization in MR297 resulted in a very low growth of root hairs. Lastly, Merah Wangi was found to be the most susceptible to drought treatment. These results are very useful for scientists if they consider any of the varieties to be fundamental to the future drought tolerance breeding program.

\section{ACKNOWLEDGEMENT}

The authors wish to express their gratitude to the Research Management Centre, International Islamic University Malaysia which provided financial support and facilities for the conduct of the research. The work presented in this manuscript came from research funded by an internal grant from the International Islamic University Malaysia (Project No. IRAGS18040-0041).

\section{REFERENCES}

Arnell, N.W., Lowe, J.A., Challinor, A.J. \& Osborn, T.J. 2019. Global and regional impacts of climate change at different levels of global temperature increase. Climatic Change 155: 377-391.

Bates, T.R. \& Lynch, J.P. 2001. Root hairs confer a competitive advantage under low phosphorus availability. Plant Soil, 236(2): 243-250.

Boonjung, H. \& Fukai S. 1996. Effects of soil water deficit at different growth stages on rice growth and yield under upland conditions. 1. Growth during drought. Field Crop Research, 48(1): $37-$ 45.

Comas, L.H., Anderson, L.J., Dunst, R.M., Lakso, A.N. \& Eissenstat, D.M. 2005. Canopy and environmental control of root dynamics in a long-term of Concord grape. New Phytologist, 167(3): 829-840. 
Dunna, V. \& Roy, B. 2013. Rice (Oryza sativa L.). In: Breeding, Biotechnology and Seed Production of Field Crops. B. Roy, A.K. Basu and A.B. Mandal (Eds.). Mandal New India Publishing Agency, India. pp. 52.

Fadhilah, Y., Foo, H.M., Sharifah, S. \& Kong, C.Y. 2012. Trend analysis for drought event in peninsular Malaysia. Jurnal Teknologi (Sciences and Engineering), 57(1): 211-218.

Fageria, N.K. 2007. Yield physiology of rice. Journal of Plant Nutrition, 30(6): 843-879.

FAO. 2018. Global Information and Early Warning System for Malaysia [WWW Document]. URL please provide URL (accessed 04.13.2020).

Farooq, M., Wahid, A., Kobayashi, N., Fujita, D. \& Basra, S.M.A. 2009. Plant drought stress: Effects, Mechanisms and Management. In: Sustainable Agriculture. E. Lichtfouse, M. Navarrete and P. Debaeke, S. Véronique, C. Alberola (Eds.). Springer, Dordrecht.

Fukai, S., Pantuwan, G., Jongdee, B. \& Cooper, M. 1999. Screening for drought resistance in rainfed lowland rice. Field Crop Research, 64(1-2): 61-74.

Gu, J.F., Yin, X.Y., Struik, P.C, Stomph, T.J. \& Wang, H.Q. 2012. Using chromosome introgression lines to map quantitative trait loci for photosynthesis parameters in rice (Oryza sativa L.) leaves under drought and well-watered field conditions. Journal of Experimental Botany, 63(1): 455-469.

Guan, Y.S., Serraj, R., Liu, S.H., Xu, J.L., Ali, J., Wang, W.S., Venus, E., Zhu, L.H. \& Li, Z.K. 2010. Simultaneously improving yield under drought stress and non-stress conditions: A case study of rice (Oryza sativa L.). Journal of Experimental Botany, 61(15): 4145-4156.

Inthavong, T., Tsubo, M. \& Fukai, S. 2011. A water balance model for characteraization of length of growing period and water stress development for rainfed low land rice. Field Crop Research, 121(2): 291-301.

Jain, M., Tiwary, S. \& Gadre, R. 2010. Sorbitolinduced changes in various growth and biochemical parameters in maize. Plant, Soil and Environment, 56(6): 236-267.

Jaleel, C.A., Manivannan, P., Wahid, A., Farooq, M., Al-Juburi, H.J., Somasundram, R. \& Panneerselvam, R. 2009. Drought stress in plant: A review on morphological characteristics and pigments composition. International Journal of Agriculture \& Biology, 11(1): 100-110.

Ji, K.X., Wang, Y.Y., Sun, W.N., Lou, Q.J., Mei, H.W. \& Chen, H. 2012. Drought-responsive mechanisms in rice genotypes with contrasting drought tolerance during reproductive stage. Journal of Plant Physiology, 169(4): 336-344.
Kawai, M., Samarajeewa, P.K., Barrero, R.A., Nishiguchi, M. \& Uchimiya, H. 1998. Cellular dissection of the degradation pattern of cortical cell death during aerenchyma formation of rice roots. Planta, 204(3): 277-287.

Laur, J. \& Hacke, U.G. 2013. Transpirational demand affects aquaporin expression in poplar roots. Journal of Experimental Botany, 64(8): 22832293.

Li, R., Guo, P., Baum, M., Grando, S. \& Ceccarelli, S. 2006. Evaluation of chlorophyll content and fluorescence parameters as indicators of drought tolerance in barley. Agricultural Science in China, 5(10): 751-757.

Khayatnezhad, M. \& Gholamin, R. 2012. The effect of drought stress on leaf chlorophyll content and stress resistance in maize cultivars (Zea mays). African Journal of Microbiology Research, 6(12): 2844-2848.

Mackay, A.D. \& Barber, S.A. 1985. Effect of soilmoisture and phosphate level on root-hair growth of corn roots. Plant Soil, 86(3): 321-331.

Mafakheri, A., Siosemardeh, A., Bahramnejad, B., Struik, P.C. \& Sohbari, E. 2010. Effect of drought stress on yield, proline and chlorophyll contents in three chickpea cultivars. Australian Journal of Crop Science, 4(8): 580-585.

Messina, C.D., Sinclair, T.R., Hammer, G.L., Curan, D., Thompson, J., Oler, Z., Gho, C. \& Cooper, M. 2015. Limited-transpiration trait may increase maize drought tolerance in the US corn belt. Agronomy Journal, 107: 1978-1986.

Metcalfe, C.R. \& Chalk, L. 1979. Anatomy of the Dicotyledons. The Clarendon Press, Oxford. pp. 100-105.

Mostajeran, A. \& Rahimi, V. 2008. Drought stress effects on root anatomical characteristics of rice cultivars (Oryza sativa L.). Pakistan Journal of Biological Science, 11(18): 2173-83.

Naumann., G., Alfiery, L., Wyser, K. Mentaschi, L., Betts, R.A., Carrao, H., Spinoni, J., Vogt., J. \& Feyen, L. 2018. Global changes in drought conditions under different levels of warming. Geophysical Research Letters, 45(7): 3285-3296.

Noraini, T. 2006. Systematic studies of Shorea, Hopea, Parashorea and Neobalanocarpus (Dipterocarpaceae) (Ph.D). University of Reading.

Ouyang, W., Yin, X., Yang, J. \& Struik, P.C. 2020. Comparisons with wheat reveal root anatomical and histochemical constraints of rice under water-deficit stress. Plant Soil, 452: 547-568.

Pandey, V. \& Shukla, A. 2015. Acclimation and tolerance strategies of rice under drought stress. Rice Science, 22(4): 147-161. 
Pandey, S., Bhahari, H., Ding, S., Prapertchob, P., Shara, R., Naik, D., Taunk, S.K. \& Sastri, A. 2007. Coping with drought in rice farming in Asia: Insights from a cross-country comparative study. Agricultural Economic, 37(s1): 213-224.

Pirasteh-Anosheh, H., Saed-Moucheshi, A., Pakniyat, H. \& Pessarakli, M. 2016. Stomatal responses to drought stress. In: Water Stress and Crop Plants: A Sustainable Approach. P. Ahmad (Ed.). Wiley, Chichester. pp.24-40 pp.

Porra, R.J., Thompson, W.A. \& Kriedemann, P.E. 1989. Determination of accurate extinction coefficients and simultaneous equations for assaying chlorophylls a and b extracted with four different solvents: verification of the concentration of chlorophyll standards by atomic absorption spectroscopy. Biochemica et Biophysica Acta (BBA) - Bioenergetics, 975(3): 384-394.

Pradhan, B., Kundu, S. \& Kundagrami, S. 2016. Shoot and root anatomy and reduce increase of aerenchyma diameter linked with submergence tolerance in rice (Oryza Sativa L.). Imperial Journal of Interdisciplinary Research, 2(11): 260-267.

Rahbarian, R., Nejadi, R.K., Ganjeali, A., Bagheri, A. \& Najafii, F. 2011. Drought stress effects on photosynthesis, chlorophyll fluorescence and water relation in tolerant and susceptible chickpea (Cicer Arietinum L.) genotypes. Acta Biologica Cracoviensia Series Botanica, 53(1): 47-56.

Salleh, M.S. 2020. Drought stress memory of primed seeds and the dynamics and resilient of anthesis quality traits in drought stress rice (Oryza sativa. L.) (Ph.D). International Islamic Univerisity Malaysia.

Salleh, M.S., Nordin, M.N., Ghaffar, M.B.A., Shahari, R., Zainuddin, Z. \& Puteh., A. 2018. Effect of preanthesis drought stress on yield components and seed quality of rice (Oryza sativa L.). Malaysian Applied Biology, 47(5): 149-155.

Sarvestani, Z.T., Pirdashti, H., Sanavy, S.A. \& Balouchi, H. 2008. Study of water stress effects in different growth stages on yield and yield components of different rice (Oryza sativa L.) cultivars. Pakistan Journal of Biological Science, 11(10): 1303-1309.
Serraj, R., McNally, K.L., Slamet-Loedin, I., Kohli, A., Haefele, S.M., Atlin, G. \& Kumar, A. 2011. Drought resistance improvement in rice: An integrated genetic and resource management strategy. Plant Production Science, 14(1): 1-14.

Singh, A.K., Shamim, M. \& Singh, K.N. 2013. Genotypic variation in root anatomy, starch accumulation, and protein induction in upland rice (Oryza sativa) varieties under water stress. Agriculture Resources, 2(1): 24-30.

Trijatmiko, K.R., Supriyanta, Prasetiyono, J., Thompson, M.J., Cruz, C.M., Moeljopawiro, S. \& Pereira, A. 2014. Meta-analysis of quantitative trait loci for grain yield and component traits under reproductive-stage drought stress in an upland rice production. Molecular Breeding, 34(2): 283-295.

Vandeleur, R.K., Mayo, G., Shelden, M.C., Gilliham, M., Kaiser, B.N. \& Tyreman, S.D. 2009. The role of plasma membrane intrinsic protein aquaporins in water transport through roots: Diurnal and drought stress responses reveal different strategies between isohydric and an isohydric cultivars of grapevine. Plant Physiology, 149(1): 445-460.

Wang, C., Li, X., Caragea, D., Bheemanahallia, R. \& Jagadish, S.V.K. 2018. Root anatomy based on root cross-section image analysis with deep learning. Computers and Electronics in Agriculture, 175: 105549

Wasson, A.P., Richards, R.A., Chatrath, R., Misra, S.C., Prasad, S.V., Rebetzke, G.J., Kirkegaard, J.A., Cristopher, J. \& Watt, M. 2012. Traits and selection strategies to improve root systems and water uptake in water-limited wheat crops. Journal of Experimental Botany, 63(9): 34853498.

Weller, S., Janz, B., Jorg, L., Krauz, D., Racela, H.S.U., Wassman, R., Butterbacth-Bahl, K. \& Kiese, R. 2016. Greenhouse emission and global warming potential of traditional and diversified tropical rice rotation systems. Global Change Biology, 22(1): 432-448.

Zhu, J., Brown, K.M. \& Lynch, J.P. 2010. Root cortical aerenchyma improves the drought tolerance of maize (Zea mays L.). Plant Cell \& Environment, 33(5): 740-749. 